\title{
Individuals' Uncertainty about Future Social Security Benefits and Portfolio Choice
}

\author{
Adeline Delavande and \\ RAND Corporation and Universidade Nova de Lisboa, Economist and Assistant Professor \\ Susann Rohwedder \\ RAND Corporation and NETSPAR, Senior Economist, 1776 Main Street, CA 90407, Santa \\ Monica, Tel: 310-393.0411, Fax: 310-451.7084, susannr@rand.org
}

\section{Summary}

Little is known about the degree to which individuals are uncertain about their future Social Security benefits, how this varies within the U.S. population, and whether this uncertainty influences financial decisions related to retirement planning. To illuminate these issues, we present empirical evidence from the Health and Retirement Study Internet Survey and document systematic variation in respondents' uncertainty about their future Social Security benefits by individual characteristics. We find that respondents with higher levels of uncertainty about future benefits hold a smaller share of their wealth in stocks.

\section{Keywords}

Expectations; Social Security; Portfolio Choice; Subjective Probabilities; Uncertainty; Health and Retirement Study

\section{Introduction}

Planning for retirement involves many intertemporal decisions, most importantly how much money to save and how to invest it. In making these decisions, individuals form expectations about a number of variables, such as future earnings and rates of return. One of these variables is future Social Security benefits, which is the major source of retirement income for 53 percent of married couples and 73 percent of nonmarried persons aged 65 or older (Social Security Administration, Annual Statistical Supplement, 2009). But despite the fact that Social Security benefits are so integral to the economic well-being of older households, previous research has noted high rates of "don't know" responses from individuals asked to project how much they expect to receive from Social Security. This has raised concerns that people are not well informed about these benefits (Gustman and Steinmeier, 2004).

Lack of knowledge about Social Security rules may explain some of the difficulties people have in forecasting their benefits. But there may be other contributing factors. For example, the level of benefits an individual ultimately collects may depend on events not yet realized before a person first claims Social Security benefits. Uncertainty regarding losing one's job or experiencing a health shock would likely influence uncertainty about future earnings used to calculate Social Security benefits. Another source of uncertainty may be the possibility of Social Security reform, which both politicians and the media mention frequently. ${ }^{1}$ Several reform proposals have been put forward: increasing payroll taxes, decreasing benefits, and 
introducing personal saving accounts. All of these would have a different influence on levels of benefits.

This uncertainty may have important ramifications, in that it is likely to influence individuals' decision-making when they plan for retirement, in particular investment decisions. Social Security benefits provide a secure, inflation-indexed, lifetime annuity. If a household could predict with certainty the Social Security benefit amount it will eventually receive, it could adjust the remainder of its investment portfolio accordingly. But what if the household is substantially uncertain about whether and/or how much it can expect? According to a basic prediction of portfolio choice theory - all else equal—someone with little uncertainty about her future Social Security benefits can afford to take on more investment risk in her remaining portfolio than someone who is highly uncertain about his future Social Security benefits. ${ }^{2}$ But because data are few, little is currently known about the extent of the uncertainty, how it varies across individuals, and how it influences economic behavior.

In this paper, we use newly available data eliciting individuals' subjective distributions about their future Social Security benefits first to describe their uncertainty about their future Social Security benefits and how it varies with observable characteristics, and second, to investigate whether the uncertainty appears to be related to households' portfolio choice. More specifically, we assess whether there is support for the hypothesis that individuals with higher uncertainty about future Social Security benefits tend to invest a smaller fraction of their wealth in risky assets. The data come from a 2007 supplemental Internet survey of a subsample of respondents to the Health and Retirement Study (HRS). The HRS is a large longitudinal survey of the U.S. population over the age of 50 . We designed the module on Social Security expectations in the 2007 Internet survey, employing an innovative visual format to elicit the distribution of individuals' subjective beliefs about the benefit amounts they might receive.

Eliciting the whole subjective distribution of future Social Security benefits has rarely been done. Several large-scale surveys-such as the core survey of the Health and Retirement Study, the Survey of Consumer Finances, and the Retirement History Survey-have asked individuals to forecast what they expect to receive in future Social Security payments. But the question design in these surveys leaves no room for expressing uncertainty, instead querying only about point estimates (e.g., "How much do you expect your monthly Social Security benefits to be?'). These data on point estimates have been used to investigate whether Social Security depresses savings (e.g., Bernheim and Levin, 1989; and Bottazzi et al., 2006) and whether it affects portfolio choice (Bottazzi et al., forthcoming).

A notable exception, however, is the Survey of Economic Expectations (SEE). Dominitz and Manski (2006), who designed the module on Social Security expectations in the SEE, elicited the minimum and the maximum and six points on respondents' subjective probability distribution of their future Social Security benefits. Based on this information they derived measures of uncertainty for each respondent. They found that both younger and older respondents showed substantial uncertainty about future Social Security benefits. They

\footnotetext{
${ }^{1}$ Social Security statements sent out to people every year also highlight the potential for Social Security reform, noting that "[Your] estimated benefits are based on current law. Congress has made changes to the law in the past and can do so at any time. The law governing benefit amounts may change because, by 2040, the payroll taxes collected will be enough to pay only about 74 percent of scheduled benefits."

${ }^{2}$ See Gollier (2002), for example. In a model that distinguishes between risky and safe assets—holding all else the same-a person who faces uninsurable background risk should invest a smaller share in the risky asset. In the case we investigate here, the background risk comes from uncertainty about future Social Security benefits.
} 
also noted that younger individuals appeared to be concerned that the Social Security system might not survive overall, but not that benefits would be reduced should the system survive.

This paper complements, as well as extends, the findings reported in Dominitz and Manski (2006) in two ways: First, it correlates individuals' uncertainty about their Social Security benefits with a rich set of covariates from the HRS, such as the subjective probability of a Social Security reform. Second, it studies the relationship between the measures of uncertainty and economic decision-making, using the example of portfolio choice. We are aware of only one other study that relates uncertainty about future public pension benefits to economic decision-making. Guiso et al. (2009) analyze the subjective distribution of public pension replacement rates among Italian workers using data obtained in a survey of a random sample of customers of a large financial institution. ${ }^{3}$ They find that higher pension risk is associated with increased investments in life insurance and with a larger likelihood to enroll in private pension funds and private health insurance plans.

The paper is organized as follows: In the next Section, we present a theoretical model of portfolio choice in which retirement age is endogenously determined. While simple, it allows us to derive our main hypothesis of how uncertainty about Social Security benefits might influence the fraction of wealth invested in risky assets. It also provides guidance regarding other factors that should enter the empirical analysis. In Section 3, we then introduce the data, discuss our analytical sample, and describe the innovative visual design we used to elicit Social Security expectations. We provide detailed descriptive statistics of how the subjective probability of receiving any Social Security benefits in the future, and individuals' uncertainty about the expected benefit amounts, both vary with observable characteristics in a multivariate setting. Note that when eliciting the uncertainty about the expected benefit amount, one could ask respondents to report the amount they expect to receive either conditional on starting to receive these benefits at a particular age or without this conditioning. In the HRS Internet module, we asked both versions of the question, randomizing across respondents. To show to what extent this leads to different empirical patterns, we present results for both.

In Section 4, we present predictors of uncertainty about future Social Security benefits. Then in Section 5, we turn to our analysis of portfolio choice and how it relates to uncertainty about expected Social Security benefits. We estimate reduced-form models that incorporate the basic implications derived from the theoretical framework. More specifically, we relate the fraction of total (non-pension) wealth held in stocks to the respondent's uncertainty about future Social Security benefits and other covariates. A challenge in the econometric analysis is that the uncertainty in Social Security benefits may be driven by uncertainty about when to claim, which may be endogenous. To deal with this endogeneity issue, we take advantage of the fact that we have various elicitation designs and mitigate the endogeneity issue by focusing on respondents who were asked their distribution of Social Security benefits conditional on a particular claiming age. Finally, in the Conclusions, we summarize our findings and suggest future avenues of research.

\section{A Simple Model of Portfolio Choice}

It is challenging to model how households allocate their investment portfolios, because some households seem to make investment decisions that are difficult to reconcile with existing theories-for example, choosing not to participate in the stock market (see Campbell, 2006,

\footnotetext{
${ }^{3}$ The elicitation method of the subjective distribution of replacement rates follows the method of Dominitz and Manski (2006) of asking respondents to first provide a minimum and maximum value, followed by questions about the chances that the replacement rate might be higher than a certain threshold. However, Guiso et al. (2009) only have one additional point on respondents subjective distribution while Dominitz and Manski elicited six additional points.
} 
for an overview of the literature). We do not aim to develop a complete model of portfolio choice. Rather, we seek to illuminate how a household's uncertainty about future pensions or Social Security benefits may influence its decisions about investing in risky assets. Because we focus on Social Security benefits, and because Social Security benefits depend on the timing of retirement, we relax the assumption of fixed labor supply common in models of portfolio choice in the finance literature (see Merton, 1990, for an overview). This is to allow for the possibility that there may be a relationship between portfolio choice and labor supply, in particular the timing of retirement: Working longer may be a form of insurance against the poor performance of previous investment decisions. Bodie and Samuelson (1989) and Bodie, Merton, and Samuelson (1992) develop theoretical models showing that for individuals with more labor supply flexibility, it is optimal to invest a larger fraction of their wealth in risky assets.

We present a simple two-period model explaining individuals' choices regarding their portfolio allocation, consumption, and retirement age. Our model is based on the two-period model developed by Bodie and Samuelson (1989). In period 1, the individual allocates his current wealth between a risky and a risk-free asset. At the end of period 1, the rate of return of the investment is realized. Given the resulting wealth, the individual decides how much to consume and when to retire. Accordingly, two important aspects of the model are that the timing of retirement is flexible, and that it is determined after the uncertainty about investment returns has been resolved. For simplicity, the individual is also assumed to claim Social Security benefits when he retires, and to consume all of his wealth in the second period.

This individual is endowed with wealth $W_{0}$ at the beginning of period 1 , and allocates a share $1-x$ of his wealth to a risk-free asset with a rate of return $r$, and a share $x$ of his wealth to a risky asset yielding $Z_{1}$ with subjective probability $p_{1}$ and yielding $Z_{2}$ with subjective probability $p_{2}=1-p_{1}$. We assume that the subjective expected return of the risky asset exceeds that of the risk-free asset: $p_{1} z_{1}+p_{2} z_{2}>r$ and that $z_{1}<r<z_{2}$. In period 2 , the individual can decide to retire at any age $A$ that we normalize so that it is between zero and 1. While still working between the ages 0 and $A$ in period 2, he earns the wage $A w$. After retiring, he earns Social Security benefits and enjoys leisure $L=1-A$ in retirement. The amount of Social Security he earns depends on how long the individual has been working. For simplicity, we assume that the Social Security formula is linear in $A$ so that an individual who retires at age $A$ gets a lifetime benefit equal to $B \times A$, where $0<B<w$.

We first consider the case in which the individual does not face any uncertainty about future Social Security benefits. The individual maximizes his expected utility. His utility function $U(C, L)$ depends on consumption $C$ and leisure $L$. We assume that $U$ is increasing, concave, and differentiable in both arguments. The individual solves the following problem:

$$
\begin{gathered}
\max _{x} E[U(C, L)]=p_{1} U\left(C_{1}, L_{1}\right)+p_{2} U\left(C_{2}, L_{2}\right) \\
\text { such that } C_{i}=W_{0}\left(1+x z_{i}+(1-x) r\right)+(w+B)\left(1-L_{i}\right) \\
L_{i}=\arg \max U\left(C_{i}, L\right) \\
\text { for } i=\{1,2\} .
\end{gathered}
$$

\footnotetext{
${ }^{4}$ Monthly Social Security benefits depend on the claiming age for two reasons. First, given a fixed earnings history, claiming later is associated with a higher monthly benefit to compensate for the fact that the worker would receive the benefits for a shorter period. This adjustment of monthly benefits is designed to be actuarially neutral so that on average Social Security wealth is unaffected by the timing of claiming. Second, if an individual who claims later also retires later, then delaying claiming changes the worker's earnings history and increases Social Security wealth for having contributed for a longer period. In our model, $B \times A$ individual's Social Security wealth, which is increasing with the length of the individual's working life.
} 
The first order conditions with respect to $L_{1}, L_{2}$ and $x$ are:

$$
\begin{gathered}
V_{L_{1}}=-(w+B) U_{C}\left(C_{1}, L_{1}\right)+U_{L}\left(C_{1}, L_{1}\right)=0 ; \\
V_{L_{2}}=-(w+B) U_{C}\left(C_{2}, L_{2}\right)+U_{L}\left(C_{2}, L_{2}\right)=0 ; \\
V_{x}=p_{1}\left(z_{1}-r\right) U_{C}\left(C_{1}, L_{1}\right)+p_{2}\left(z_{2}-r\right) U_{C}\left(C_{2}, L_{2}\right)=0 .
\end{gathered}
$$

The first-order condition with respect to $x$ implies that the risk-averse individual will invest a positive share in the risky asset. This is because at $x=0$, we have $C_{1}=C_{2}$ and as a result, $L_{1}=L_{2}$. So $V_{x}>0$ at $x=0$. For the first-order condition to hold, one needs to increase $x$.

We next consider the case in which there is uncertainty in Social Security benefits. Suppose that Social Security benefit $b$ is a random variable that is independent of $z$ and has the same expected value as in the certainty case above $E(b)=B$. The random variables $b$ and $z$ are assumed to be realized at the same time. We have the following results:

\section{Proposition 1}

Suppose the individual's utility function is of the following form:

$$
\begin{gathered}
U(C, L)=\log \left(C-C_{0}\right)+\beta \log \left(L-L_{0}\right), \\
\text { or } U(C, L)=\frac{\left(C-C_{0}\right)^{\alpha}\left(L-L_{0}\right)^{\beta}}{\alpha},
\end{gathered}
$$

with $\alpha>0, \beta>0,0 \leq C_{0}<W_{0}, 0 \leq L_{0}<1-\left(\frac{1+z_{2}}{B+w}\right)$.

Introducing uncertainty about Social Security benefits reduces the optimal fraction of total wealth invested in the risky asset.

\section{Proof}

The proof is presented in Appendix A.

Note that the utility functions specified above comprise utility functions that have constant relative risk aversion with respect to $C$ when $C_{0}=0$, and utility functions that have decreasing relative risk aversion with respect to $C$ when $C_{0}>0 .{ }^{5}$

This simple model implies that higher uncertainty about future Social Security benefits should be associated with a smaller fraction of total wealth invested in stocks. In Section 5, we will assess whether there is empirical support for this. For simplicity, we assume that there is no correlation between stock market returns and Social Security benefits. A positive correlation between the two should reduce the individual's demand for the risky asset.

As pointed out by Bodie and Samuelson (1989), this model further implies that younger workers can take on more investment risk than older workers, because they have a longer time horizon during which they can adjust their labor supply in response to any adverse portfolio outcomes.

It is also useful to establish in the context of this model what quantities the individual would report if asked in period 1 for his or her subjective expectations about Social Security benefits. The benefit amount depends on the retirement age which in turn depends on the

\footnotetext{
${ }^{5}$ The upper bounds on $C_{O}$ and $L_{O}$ ensure an interior solution for $C_{i}$ and $L_{i}, i=1,2$.
} 
investment returns which are not yet known in period 1 . Therefore, the individual would report the distribution of $p_{1} b A_{1}+p_{2} b A_{2}$. Note that it depends on the individual's expectations about stock market returns in period 1 , given by $p_{1}$ and $p_{2}$. However, if the individual was asked about his or her subjective distribution of Social Security benefits conditional on claiming at age $A_{1}$, the individual would report the distribution of $b A_{1}$. The distribution of benefits conditional on a claiming age has therefore a smaller variance than that of the distribution unconditional on a claiming age, and does not depend on expectations about stock market returns.

\section{Data on Social Security Expectations}

\subsection{The HRS Internet Survey and our Analytical Sample}

We use data on Social Security expectations that come from the second wave of the HRS Internet Survey, a supplementary survey of the Health and Retirement Study (HRS). The HRS is a panel survey representative of the U.S. population age 51 and over. In the core survey, the HRS collects biennial data on close to 20,000 individuals and their spouses in about 13,000 households. ${ }^{6}$ Eligibility for the second wave of the HRS Internet Survey was determined by whether a respondent reported in the HRS 2004 or 2006 core survey that he or she regularly used the Internet. Eligible respondents were divided into two groups. The first was invited to participate in the survey in the spring of 2006 (called phase I) and the second in the summer of 2007 (called phase II). ${ }^{7}$ We link the data from the HRS Internet survey to the HRS 2006 core survey to obtain additional covariates on the same respondents. Therefore, our various samples of analysis are composed of those respondents who answered the relevant questions about Social Security in the HRS Internet survey and who also responded to the HRS 2006 wave.

In this paper, we focus on two aspects of respondents' Social Security expectations: (i) the subjective probability of receiving Social Security benefits at some time in the future and (ii) the subjective distribution of future Social Security benefits, conditional upon receiving them. Only respondents who were not currently receiving Social Security benefits were asked about these items. Exactly 1,500 respondents from phases I and II of the second wave of the HRS Internet survey reported not receiving Social Security benefits at the time of the interview. 1,489 provided a percent chance when asked about the probability of receiving Social Security benefits in the future. Of those, $5 \%$ said there was a zero percent chance that they would receive Social Security benefits in the future. Consequently, this 5\% were not asked any further questions about their expectations regarding Social Security benefits.

For the analysis of uncertainty about future Social Security benefit amounts our analytical sample is smaller. This is because we experimented with two alternative formats for their elicitation. Half the sample was administered a sequence of percent chance questions similar to the design in the SEE by Dominitz and Manski, and the other half was administered a visual format that we designed and describe in detail below. ${ }^{8}$ In this study we focus our analysis of uncertainty about future Social Security benefits on respondents who were

\footnotetext{
${ }^{6}$ Spouses of age-eligible respondents are included irrespective of age.

7 The interview was postponed for one group of the sample to a later second phase because that group had previously been assigned (at random) to participate in another supplemental study. It would have had three HRS-related interviews within a few months of each other had the internet interview not been postponed.

${ }^{8}$ The purpose of using two different elicitation formats was to evaluate the impact of the elicitation design on respondents' answers (see Delavande and Rohwedder, 2008). Delavande and Rohwedder (2008) find that in the visual format the observed distributions tend to be more concentrated around the point estimate than the percent chance format. Additional experiments lead us to conclude that this is not due to anchoring toward the middle in the bins-and-balls format. In addition, 20 percent of the observations randomized into the percent chance format are lost due to violation of the monotonicity property of a cumulative distribution, and those 20 percent tend to be less educated, less healthy and less wealthy. We have therefore decided to focus our analysis on respondents randomized into the visual formats.
} 
randomized into the visual format (783 respondents, of whom 774 also participated in the HRS 2006 core survey). As noted in Section 2, one can ask individuals about the benefit amount they expect to receive with or without conditioning on a particular age at which the individual would first receive the benefits. We did both and once again randomized which set of respondents received which format (nobody was asked both). We take advantage of the availability of observations of uncertainty both conditional and unconditional upon the expected claiming age (albeit on different samples of respondents) in our empirical analysis of portfolio choice and how it relates to uncertainty about future Social Security benefits. Item non-response on the Social Security-related questions in the HRS Internet survey is very low (less than $2 \%$ ).

Table 1 gives the characteristics of our analytical sample. 1,479 of HRS Internet respondents report a probability of receiving Social Security in the future and answered the 2006 HRS core survey. ${ }^{9}$ Among those, the average and median age is 56 (90\% of our sample is between 50 and 65), 62\% are female, $78 \%$ are married, $84 \%$ are working for pay (and the average length of working life to date is 29 years). The number of years spent in education is 14 years both at the mean and at the median. When looking at the highest achieved degee, $27 \%$ have a high-school degree or less, $32 \%$ have some college, and $41 \%$ have completed college or more. Characteristics of those randomized into the visual format are similar.

As one would expect for a sample selected on the basis of Internet usage, this pool of respondents is more educated and more likely to work than the general population of the same age. For example, among the HRS 2006 respondents between the ages of 50 and 65 who do not currently receive Social Security, $39 \%$ have a high-school degree or less, $28 \%$ have some college, $32 \%$ have completed college or more, and $79 \%$ are currently working. ${ }^{10}$

\subsection{Expectations about Social Security: Survey Design and Descriptive Statistics}

All HRS Internet respondents in phase I and phase II who reported not currently receiving Social Security benefits were asked:

On a scale from 0 to 100 , (where 0 means no chance and 100 means absolutely certain), what do you think is the percent chance that you will receive Social Security benefits some time in the future?

Most respondents gave a high chance of receiving Social Security benefits in the future. The median and average subjective probabilities are $90 \%$ and $79 \%$ respectively (Table 1). Five percent of respondents answered 0\%, 13 percent said 50\%, and 40 percent said $100 \%$.

Respondents who provided a positive probability of receiving Social Security at some time in the future were then instructed to assume for subsequent questions that they would, in fact, receive benefits:

Suppose that you will indeed receive SS benefits in the future. We will ask some questions about when you expect to receive them and how much you think they will be.

These respondents were then asked about the timing of claiming:

At what age do you expect to start collecting these benefits?

In phase II of the HRS Internet survey, we used a visual format to elicit information on individuals' subjective probability distributions about their future Social Security claiming

\footnotetext{
${ }^{9}$ In our regressions, we exclude two respondents for whom education is missing. We also exclude from the analysis of uncertainty respondents who report a monthly Social Security benefit above $\$ 10,000$ (11 respondents).

${ }^{10}$ The percentages for the HRS 2006 are based on weighted data.
} 
age in a way that mimicked the density function of their subjective beliefs. ${ }^{11} \mathrm{We}$ asked respondents to allocate 20 balls into 8 bins, each representing a claiming age, to express the likelihood that they would first claim benefits at each age. The left outer bin represented age 61 or younger, while the right outer bin represented age 68 or older. On a first screen, we presented a short introduction to familiarize respondents with the exercise. The next screen, replicated in Figure 1, showed an example with 12 balls allocated in the bin for age 64, and 8 balls in the bin for age 65, and described this particular allocation. Finally, on the third screen-similar to that of Figure 1, except with all 20 balls placed in a box beneath the bins -respondents were asked to allocate all the balls into the 8 bins to express the chances out of 20 that they would claim at each age.

The distribution of point estimates for the claiming age exhibits heaping at ages 62 (27\% of answers) and 65 (30\% of answers). Only 14\% report their normal retirement age at which they qualify for full Social Security benefits as their expected claiming age. Respondents tend to have subjective probability distributions concentrated around the reported expected claiming age: $47 \%$ of respondents allocate all of the probability mass within one year of the reported expected claiming age and $76 \%$ allocate at least $75 \%$ of the probability mass within one year of the expected claiming age.

Next we asked respondents about the amount of their expected future Social Security benefit. The elicitation method followed a sequence similar to that in the elicitation of the distribution of the expected claiming age. Respondents who reported a positive probability of receiving Social Security benefits in the future were first asked to give a point estimate about their future benefits, conditional on receiving any:

How much do you expect your monthly Social Security benefits to be in today's dollars?

For half the sample we then again used a visual format to elicit the subjective distributions of benefits conditional on future receipt. ${ }^{12}$ Respondents were presented with an introduction and an example and were asked to allocate 20 balls into the 7 bins so that the allocation would reflect the chances out of 20 that their monthly Social Security benefits would fall into any one of the possible dollar ranges (see Figure 2). The example was the same for all respondents. But on the screen where respondents would allocate the balls themselves the thresholds for the bins were tailored to each individual respondent and centered around his or her point estimate of expected future Social Security benefits. The left outer bin ran from zero to $30 \%$ of the respondent's point estimate (rounded to the next 5 dollars); each of the middle five bins covered an equal range (interval amounting to $30 \%$ of the respondent's point estimate). The right outer bin was open-ended, as shown in Figure 2. If a respondent did not provide a point estimate, we administered standardized thresholds centered around $\$ 1,100$.

Phase II respondents who allocated all of the balls into one or two adjacent bins were presented with a follow-up bins-and-balls screen. These "unfolding bins" split the initial range containing all the balls into narrower bins of equal width. The respondents were asked to place 20 balls into those narrower bins (see Delavande and Rohwedder, 2008, for the exact wording presented to the respondents). The number of new bins varied between 2 and 5 , depending on the size of the range to which the respondent had initially allocated all of the probability mass. ${ }^{13}$

\footnotetext{
${ }^{11}$ Both phase I and phase II respondents were asked to report the point estimate of their expected claiming age. The distribution of claiming ages was only administered to phase II respondents ( $\mathrm{N}=1,021$, with item non-response equal to $0.4 \%)$. All Phase II respondents were asked first their expected claiming age, and then their subjective distribution of claiming ages.

12 As mentioned earlier, the other half of the sample was also asked about their uncertainty about the Social Security benefit amount, but using a different survey design (a sequence of percent chance questions).
} 
The design above elicits expected Social Security benefits without asking respondents to assume that they would claim at a particular age. Within the sample of respondents assigned to the visual format, respondents were further randomized into two subgroups: 59\% of the sample were asked to report their distribution of Social Security benefits unconditional on their claiming age, as just described above; the other $41 \%$ were asked to report their distribution of future Social Security benefits conditional on claiming at their point estimate of their expected claiming age. ${ }^{14} \mathrm{We}$ conducted this experiment because little is known about how conditioning on a particular claiming age affects the distribution of Social Security benefits elicited. ${ }^{15}$ The timing of when a person first claims Social Security benefits determines the benefit amount in important ways-first, because of how benefits are computed and second, because of the potential additional earnings for respondents who work longer. For someone who first claims at the normal retirement age (NRA, which is 66 for most respondents in our sample), ${ }^{16}$ the monthly benefit equals $100 \%$ of the Primary Insurance Amount (PIA), which itself depends on past earnings. However, individuals can claim benefits as early as age $62 .{ }^{17}$ Holding retirement age and lifetime earnings constant, if an individual claims between age 62 and his or her NRA, there is an actuarial reduction in the benefit for each month of claiming before the NRA. ${ }^{18}$ If he or she claims after the NRA, there is a delayed-retirement credit that increases until age 70. Most people start claiming Social Security benefits at about the same time as they retire. As a result, the PIA will differ if someone claims early rather than late, due to the additional earnings. A person's uncertainty about his or her expected Social Security claiming age therefore ought to be strongly reflected in that person's uncertainty about the benefit amount unconditional on claiming age.

The $25^{\text {th }}, 50^{\text {th }}$, and $75^{\text {th }}$ percentiles of the distribution of the expected monthly benefit amount unconditional on the expected claiming age are $\$ 750, \$ 1,100$, and $\$ 1,500$ respectively. For the distribution of the expected monthly benefit amount conditional on expected claiming age, those same percentiles are closely comparable: $\$ 750, \$ 1,000$, and $\$ 1,500$ (Table 1). Both distributions-conditional or unconditional on expected claiming age - tend to center around the point estimate. ${ }^{19}$ Respondents allocate, on average, $60.3 \%$ of the probability mass to the middle bin (which covers the range of plus/minus 15\% around the point estimate), $17.2 \%$ to the bin immediately to the left of the middle bin, and $16.6 \%$ to the bin immediately to the right of the middle bin. The outer bins attract low probability mass overall.

\footnotetext{
${ }^{13}$ If all probability mass was allocated to a range between $\$ 300$ and $\$ 450$ in the first screen, respondents were provided a follow-up screen with 2 bins. If that initial range was between $\$ 450$ and $\$ 600$, the follow-up screen contained three bins. If the initial range was between $\$ 600$ and $\$ 750$, the new screen contained four bins. If the initial range was above $\$ 750$, the new screen contained five bins.

${ }^{14}$ Those in the first group were asked about their expected benefits first, followed by questions about when they would expect to claim these benefits. The second group, that is, those who were asked to condition on their expected claiming age when reporting their benefits expectations, naturally were first asked their expectations about claiming age, and then their expectations about Social Security benefits.

${ }^{15}$ The HRS core survey asks about the point estimate of expected Social Security benefits conditional on claiming at the stated (point estimate of) expected claiming age.

${ }^{16}$ The normal retirement age depends on the individual's year of birth, and ranges from 65 to 67 in our sample.

${ }^{17} \mathrm{~A}$ widowed person can claim as early as age 60 .

${ }^{18}$ For example, workers whose normal retirement age is 66 receive a benefit equal to $75 \%$ of the PIA if they claim on their $62 \mathrm{nd}$ birthday (e.g., Coile et al., 2002).

${ }^{19}$ This may raise the concern that the middle bin attracts excessive probability mass due to anchoring bias. This is not the case as we found from experiments that we conducted in a different Internet survey (Delavande and Rohwedder, 2008). We randomly administered to some respondents the same visual format as is done in the HRS Internet survey, and to other respondents a similar design where the third, rather than the middle bin is centered around the point estimate. We find that for both groups, most of the probability mass is attracted to the bin containing the point estimate, even though for one group this bin is not located in the middle.
} 


\section{Predictors of Uncertainty about Social Security Benefits}

Intuitively one can think of a number of factors that might affect individuals' expectations about Social Security: for example, outcomes of future events that affect the calculation of benefits (e.g., future earnings or the timing of retirement), the possibility of a recession affecting earnings and therewith Social Security benefits; or political risk with respect to Social Security reform. But there could also be variation in expectations of a very different nature resulting from inattention. For example, a very wealthy person might not care to know what amount he or she is entitled to because it accounts for too small a fraction of retirement resources. Research on models of expectation formation is still in its infancy. Therefore we do not know exactly how these factors might enter the expectation formation process. In what follows, we show descriptive multivariate regressions of Social Security expectations on potential determinants.

The uncertainty that so many respondents show about their future Social Security benefits can be decomposed into their uncertainty about eligibility and their uncertainty about the benefit amount conditional on being eligible. Because each of these two components is of separate interest we conducted separate analyses of how they relate to observable characteristics. For completeness, we also analyzed how characteristics are related to the central tendency of the distribution of Social Security benefits.

We used the elicited subjective probability of receiving Social Security benefits in the future as a measure of uncertainty about eligibility. To facilitate our analysis of the distribution of benefits, we made parametric assumptions similar to those of Engelberg et al. (2009) to fit a distribution to respondent's answers. In particular, we assumed that the subjective distributions with positive probability in at least three bins were of generalized beta form, and that the subjective distributions based on one or two bins were isosceles triangular (See Appendix B). We then used the mean of the fitted distribution as a measure of central tendency, and the standard deviation as a measure of uncertainty. If we use the median and interquantile range instead, we find similar results (results not shown).

Regarding the uncertainty about Social Security benefits, we conducted separate analyses for respondents who were asked their distribution conditional or unconditional on their expected claiming age. When we asked respondents to report their distribution conditional on a particular claiming age, they presumably provided a distribution of beliefs that does not incorporate uncertainty about the claiming age.

In this context, a question arises: Which feature of the distribution of claiming ages (e.g., the mean, mode, median, or another quantile) do respondents report when they are asked what they expect the point estimate of their claiming age to be? We investigated this question by assuming that the distribution on claiming age is discrete and that its support is between 60 and 70 (see Appendix $\mathrm{C}$ for the details of these assumptions). We find that the reported point estimate for the claiming age is consistent with the mode for $90 \%$ of the respondents, with the median for $76 \%$ of the respondents, and with the mean for $52 \%$ of the respondents.

Table 1 shows some descriptive statistics of the standard deviations of the fitted distributions. Several patterns are of interest. First, respondents exhibit considerable uncertainty about their future monthly benefit amount conditional on being eligible: The average standard deviation is about $\$ 105$, which is about $9 \%$ of average expected benefits. ${ }^{20}$

\footnotetext{
${ }^{20}$ Note that we find less uncertainty than Dominitz and Manski (2006). They report that the cross-sectional median of the subjective interquartile range of yearly benefits is $\$ 7,140$, while it is $\$ 1,296$ in our data for the distribution unconditional on claiming age. This difference may be due to the fact that their sample is younger on average than ours (41.8 years old, in contrast with 55.9 years old). As we explain below, younger respondents report more uncertainty about future benefits.
} 
Second, the degree of uncertainty varies within the population: The interquantile range of the standard deviation ranges between $\$ 83$ and $\$ 88$. Finally, all of the quantiles of the distribution of standard deviations are higher for the unconditional format than for the conditional format, suggesting, as one would expect, that respondents who are asked their beliefs unconditional on a claiming age exhibit more uncertainty.

Table 2 presents the Best Linear Predictors under square loss that relate the various measures of Social Security expectations to a number of variables: socio-economic characteristics; factors that influence eligibility according to current rules, such as the total number of years worked; future earnings, such as the subjective probability of losing one's job or the probability of an economic recession in the next 10 years; and the subjective probability that Social Security reform will take place in the next 10 years so that benefits become less generous than they are now. Table 1 provides descriptive statistics of those variables.

The first column in Table 2 shows that age is an important predictor of the probability of receiving Social Security in the future. Respondents in their late 50s and early 60 s provide a higher probability of receiving future benefits than those in their early 50 s or younger. Respondents age 50 to 54 have, on average, a subjective probability of benefit receipt 6 percentage points lower than that of respondents age 55 to 59 . This is consistent with the fact that an individual's uncertainty about what the structure of Social Security will look like at the time of his or her first claim should decrease as the time of claiming draws near.

In addition, variables related to current eligibility rules are clearly important predictors: Respondents who work, and those who have been working longer, report a higher probability that they will receive Social Security in the future. On average, respondents who work provide a subjective probability of eligibility 8 percentage points higher than those who do not work. This is consistent with the fact that under current law, only individuals who have worked 10 years or more are eligible to receive benefits based on their own work record. Concerns about Social Security reform, as well as about the state of the economy (which may influence the type of reform that takes place), are associated with the subjective probability of being eligible. Conditioning on other covariates, those who think there is a higher chance of Social Security reform and of a recession within the next 10 years provide a lower probability that they will receive any benefits in the future.

The second column of Table 2 shows how observable characteristics relate to the mean of the fitted distribution of the benefit amount. For this variable, we pooled respondents from the conditional and unconditional format together, because the format does not seem to influence how characteristics are related to the mean (tables not shown). We did, however, add an indicator for the elicitation format. Variables that are known to affect lifetime earnings (and thus the PIA), such as gender, education, and number of years worked, are dominant predictors. In addition, individuals who report a lower subjective probability of Social Security reform have a lower mean. This finding, combined with the results shown in Table 1, is consistent with the idea that individuals fear that the system will either disappear entirely, or that benefits will be reduced.

Looking at the last two columns of Table 2, we see that the important predictors of the probability of eligibility are different from those of the uncertainty about the amount conditional on being eligible. Interestingly, the coefficients associated with the subjective probability of an economic recession and Social Security reform are not precisely estimated in the benefit amount specification. But this result may be due to the smaller sample size.

An important predictor of uncertainty about the amount of future benefits is the individual's distance to the expected claiming age. ${ }^{21}$ The coefficients of Table 2 are consistent with the 
idea that those who are further away from claiming face more unresolved uncertainty about events that may influence the benefit amount. But even people who are less than 5 years away from retirement still report uncertainty (in this group, the average standard deviation of monthly benefits is \$90). In general, women - in addition to reporting a lower average benefit amount than men-report less uncertainty about future benefit amounts than their male counterparts.

The coefficients in columns 3 and 4 exhibit similar patterns overall. In Column 4 , we see that the uncertainty about the timing of claiming, as measured by the standard deviation of the distribution of claiming ages, is positively associated with uncertainty about the expected benefit amount and has a very large coefficient. ${ }^{22}$

Lack of knowledge of the rules that govern Social Security benefits may be an important determinant of uncertainty. But unfortunately, we have limited data on people's knowledge about the Social Security program. We observe whether a person knows that filing claims early results in reduced benefits: 23 We have created an indicator for knowledge about this feature of the rule. It turned out not to be a statistically significant predictor of uncertainty and including it did not change any other coefficients. We therefore do not present it in Table 2 .

\section{Uncertainty about Future Social Security Benefits and Portfolio Choice: Empirical Analysis}

Social Security benefits are the main source of retirement income for the majority of retirees. But in Section 4, we show that many respondents-including those close to their expected claiming age- exhibit uncertainty about the level of benefits they expect to receive. The theoretical model we presented in Section 2 indicates that individuals who face more uncertainty in their Social Security benefits invest a smaller fraction of their wealth in risky assets. In this section, we investigate this premise empirically. To this end, we estimated a reduced-form model, taking into consideration the uncertainty that individuals face with respect to both the uncertainty related to their eligibility for benefits and that related to the benefit amount, i.e., the distribution of benefits unconditional on eligibility. ${ }^{24}$ We estimated an equation of the form:

$$
x_{i}=\alpha s d_{i}+\beta Z_{i}+\varepsilon_{i},
$$

where $x_{i}$ denotes the fraction of wealth held in stocks by the household in which individual $i$ lives, $s d_{i}$ denotes the standard deviation of $i$ s subjective distribution of Social Security benefits, $Z_{i}$ denotes individual and household characteristics, and $\varepsilon_{i}$ is an unobserved random term. On average, individuals in our sample hold $14 \%$ of their total assets in stocks;

\footnotetext{
${ }^{21}$ We include categorical variables for both age and the distance to the expected claiming age. While younger respondents have on average a larger distance to the expected claiming age, there is heterogeneity in this variable within age categories, in particular among the 50-to-59-year-olds.

${ }^{22}$ To compute the standard deviation of the distribution of claiming ages, we treat claiming ages as a discrete random variable distributed between 60 and 70 . Those who report a positive probability to the interval "61or less" are assumed to have allocated half of this probability to age 60 , and half of it to age 61 . We make similar assumptions for those who report a positive probability for the interval "68 or more."

${ }^{23}$ In 2006, respondents younger than 62 were asked their expected benefits if they were to claim at age 62 and if they were to claim at their normal retirement age. Of those who were asked both questions, 53\% correctly provided a lower benefit amount for claiming at age 62 than for claiming at the normal retirement age, 10\% made a mistake (that is, they reported an equal or higher amount at age 62 than at the normal retirement age), and 37\% answered "don't know" to at least one of the questions about the expected benefit amounts.

${ }^{24}$ The standard deviation of the distribution of the benefit amount unconditional on eligibility is given by the product of the probability of being eligible and the standard deviation of the distribution of the benefit amount conditional on eligibility.
} 
the median is $3 \%$ (Table 1). Forty-five percent of the households in which our respondents live do not hold any stocks. (Note that the fraction of wealth invested in stocks is a household-level variable from the HRS 2006 core survey). ${ }^{25}$ In addition to uncertainty about their own future benefits, married individuals in our sample may have uncertainty about their spouse's Social Security benefits. However, we do not have any information on this variable.

As we explained in Section 3.2, information is available on the distribution of Social Security unconditional on the expected claiming age (i.e., the distribution of $p_{1} b A_{1}+p_{2} b A_{2}$ in the model) for some respondents, and for other respondents, conditional on an expected claiming age (the distribution of $b A_{1}$, for example, if the respondent reports the most likely claiming age as expected claiming age and $p_{1}>p_{2}$ ). In this simple framework, answers about $b A_{1}$ should capture the uncertainty associated with $b$. In practice, an individual who delays claiming may work longer. As a result of the additional years of earnings, his PIA may increase. But because there may be uncertainty about future earnings close to retirement (i.e., in $w$ in our model), this individual may exhibit more uncertainty about future Social Security benefits conditional on claiming late than conditional on claiming early. As such, the standard deviation of the distribution unconditional on a claiming agewhich supposedly also captures uncertainty about lifetime earnings for all potential claiming ages-would better capture the uncertainty that individuals consider when making their portfolio choice than would the standard deviation of the distribution conditional on a claiming age.

However, using the standard deviation of the distribution unconditional on the expected claiming age poses some econometric challenges. By definition, this standard deviation depends on the subjective distribution of stock market returns, because those influence the retirement age, which is not precisely measured in the HRS. As a result, it may be correlated with the random term $\varepsilon_{i}$. To deal with this issue, one could use an instrumental variable approach, but we do not have a suitable instrument. Instead, we used the standard deviation of the distribution of Social Security benefits conditional on a claiming age. The underlying assumption is that this uncertainty, which depends on factors such as the probability of reform, is exogenous to unobservable variables that influence portfolio choice. But this standard deviation may underestimate the overall uncertainty that individuals face. Consequently our estimate may provide a lower bound of the effect of uncertainty about future Social Security benefits on portfolio choice.

Our theoretical framework suggests a number of other covariates we should include in our reduced-form model. People's subjective beliefs about stock market returns are critical to their portfolio choice. We used (1) the elicited subjective probability that the price of mutual fund shares invested in blue chip stocks, such as those in the Dow Jones Industrial Average, will increase faster than the cost of living over the next 10 years, (2) the subjective probability that it will increase by 8 percent or more per year on average over the next 10 years, and to complement these measures (3) the subjective probability that there will be an economic recession within the next 10 years.

Risk-aversion is another important factor in portfolio choice and we used it too as a covariate. The HRS includes a categorical measure of risk-aversion derived from a set of questions where the respondent is asked to choose between two jobs, where one guarantees

\footnotetext{
${ }^{25}$ All components of wealth in the HRS are measured at the household level. Total wealth is defined as the sum of the following assets: housing, other real estate, transportation, IRAs, stocks and stock mutual funds, checking and savings, CDs, bonds, and other assets, minus all debt (mortgages, home equity loans, and any other debt). With respect to IRAs, respondents are asked what fraction of the balance is invested in stocks. We applied these reports to the respective IRA balances to recover the amount held in stocks.
} 
the current family income and the other offers a chance to increase income, but also carries the risk of income loss. As we point out in Section 2, the time horizon may additionally be important, so we controlled for age and a measure of subjective survival expectations relative to the life table (i.e., the ratio of the subjective probability of being alive at age 75 to the probability given by the life table). We used education as a covariate as well, because a more educated individual may be more able to insure his risky investment with labor income. Finally, we controlled for the level of total wealth, including expected Social Security entitlements. We created an indicator for total bequeathable wealth (above and below the median in our sample, referred to as "other wealth" in Table 3) and an indicator for Social Security wealth as measured by the mean of the fitted distribution of Social Security benefits (above and below the median), and interacted the two. We also included an indicator for whether the individual has an employer pension.

Table 3 shows the best linear predictors of the fraction of wealth held in stocks under square loss. The first column uses the standard deviation of the fitted distribution of Social Security benefits unconditional on claiming age as the measure of uncertainty, while the second column uses the standard deviation of the distribution conditional on the expected claiming age. The second column therefore presents our preferred estimates, as conditioning on the expected claiming age reduces the problem of endogeneity. Focusing on this column, we find, as predicted by the theoretical model, that individuals with more uncertainty about their future Social Security benefits are less likely to hold a greater portion of their wealth in stocks, and the coefficient is statistically significant at $5 \%$. All else equal, increasing the standard deviation from the $25^{\text {th }}$ to the $75^{\text {th }}$ percentile reduces the fraction of wealth held in stocks or bonds by $0.017 .^{26}$

Turning to those expectations related to the stock market or economy, we see that individuals who report a higher subjective probability that the price of stocks will rise faster than the cost of living over the next 10 years, or a lower subjective probability of a recession, hold a higher fraction of their wealth in stocks. Contrary to what the model predicts, Table 3 shows that older individuals have a higher share of their assets in stocks. This may be due to the fact that younger households may be more likely to face borrowing constraints, which may make risky financial investments less attractive to them (Campbell, 2006). However, individuals with more education tend to hold a higher proportion of their assets in stocks. The coefficients associated with the measures of risk aversion here are not precisely estimated, which may be due to the fact that the hypothetical questions about job loss do not do a very good job of capturing risk-aversion related to financial investments.

Table 3 also shows interesting patterns related to wealth: Those with high other (bequeathable) wealth and high Social Security wealth invest by far the largest proportion of their assets in stocks (almost 10 percentage points more than the other groups).

The coefficients associated with the standard deviations of the distribution of benefits unconditional on claiming age is much smaller in magnitude than the one for the distribution conditional on claiming age. This may suggest that endogeneity is indeed an issue with the unconditional distribution, and that using the distribution conditional on an expected claiming age mitigates that problem.

Overall, the results presented in Column 2 based on the conditional distribution favor the hypothesis that individuals who exhibit less uncertainty about their future Social Security benefits hold more risky investment portfolios. Under the assumption that using the

\footnotetext{
${ }^{26}$ Table 3 excludes respondents who report a zero probability of receiving Social Security in the future. Those have a zero mean and a zero standard deviation. Including them, while adding an indicator for reporting a zero probability, does not change our results.
} 
conditional distribution eliminates the endogeneity problem and that no other omitted variables bias the estimated relationship, these relationships can be interpreted as causal. In that sense, our results suggest that our respondents act qualitatively as theory would predict. However, they do not allow us to determine whether individuals choose the optimal amount of risky investment given the Social Security benefits they expect.

It is possible, though, that these results could be driven by some omitted variables. This would happen if, for example, lower levels of uncertainty were positively correlated with higher financial literacy or cognitive ability (and thus better knowledge of Social Security rules), and, in turn, if individuals who are more financially savvy are more likely to hold a larger portion of their wealth in stocks. Our specification includes controls for gender and education, which have been found to be important indicators of financial literacy (Lusardi and Mitchell, 2007) ${ }^{27}$ But we cannot rule out that this may be an important variable whose effect is not fully captured by the controls for gender and education.

Another issue may be related to the correlation between expectations about stock market returns and Social Security benefits. Such a correlation would occur, for example, if people believed that a correlation exists between the growth of their earnings and returns on stocks, or that a Social Security reform that would reduce benefits is more likely to happen when stock returns are low. In Table 1, we find that individuals who report a higher probability of a recession within the next 10 years report a lower probability of eligibility, which may indicate that a positive correlation does exist between stock market returns and Social Security expectations. This correlation would be problematic for our analysis of portfolio choice if it were to vary systematically across individuals and influenced their portfolio choice. But at this point, we do not have the information on the joint subjective distribution of benefit amounts and stock market returns that would enable us to establish whether this is indeed the case.

\section{Conclusions}

In this paper, we have presented empirical evidence concerning the uncertainty individuals have about their future Social Security benefits, and how this uncertainty influences their portfolio choice. The evidence is based on a new data collection method that we applied in the HRS Internet survey.

We document sizeable uncertainty about respondents' eligibility for Social Security benefits, as well as the amount of benefits they expect to receive. We find that younger respondents and those further away from their expected claiming age exhibit greater uncertainty, suggesting that uncertainty related to events that have not yet happened may be relevant. In line with this idea, we also find that higher subjective probabilities of either Social Security reform or of a recession within the next 10 years are associated with a lower probability of eligibility. However, those variables appear not to predict uncertainty in the expected Social Security benefit amount. But this could be due to the much smaller sample size in the analysis of the uncertainty about expected benefit amounts.

We describe associations between expectations and observable characteristics, but are unable to conclude whether the relationships are causal. Having panel data on individuals' uncertainty about Social Security benefits -ideally on a larger sample — would enable us to make some progress in determining what factors are relevant when people form their expectations about future Social Security benefits. More specifically, it would be very

\footnotetext{
${ }^{27}$ In an alternative specification, we have also included the measures of Social Security knowledge described earlier to proxy for financial literacy. They were imprecisely estimated and other coefficients were unaffected by their inclusion.
} 
valuable to have panel data on expectations, combined with data on the information that respondents receive between waves. Because collecting data on the changes in the information set between waves may be challenging, researchers could alternatively randomly provide "information treatments" to some respondents and not to others and evaluate how those treatments change expectations. In this context, it would also be of interest to have additional information on other potential determinants of uncertainty about benefits, such as the subjective distribution of a spouse's claiming age and benefits.

In terms of the question of whether uncertainty about Social Security expectations influences portfolio choice, we faced the challenge that the uncertainty associated with the distribution of Social Security benefits unconditional on a claiming age may be endogenous, given that expectations about stock market returns may influence the subjective distribution of claiming ages. We mitigated this endogeneity problem by using the uncertainty associated with the distribution of Social Security benefits conditional on a claiming age. Our results suggest that individuals with more uncertainty about their future Social Security benefits tend to hold a smaller portion of their wealth in stocks. The magnitude of the estimated effect is likely an underestimate, because the uncertainty about Social Security benefits is bound to be smaller when measured conditional on a claiming age as opposed to when measured without such conditioning.

Admittedly, we cannot say for certain that the standard deviation of the conditional distribution in Social Security benefits is not correlated with unobservable variables that may influence portfolio choice. Specifically, it may be that expectations about Social Security benefits and stock market returns are correlated and that this correlation may influence portfolio choice. To find out, one would have to elicit the joint subjective distributions from survey respondents. To our knowledge, this has never been done. Future research will have to show whether eliciting the joint distribution is feasible, and whether, in our context, such correlation is empirically important.

\section{Acknowledgments}

This research was supported by a grant from the National Institute on Aging (P01AG008291 and R01AG20717). Delavande also acknowledges support form a NOVA Forum research grant. The authors thank the Health and Retirement Study (HRS) for providing the opportunity to include our module in the HRS Internet Survey. They also thank the participants of the workshop on "Subjective Beliefs in Econometric Models" held in Québec City in 2009, in particular Charles Bellemare and Chuck Manski, two anonymous referees and Luis Vasconcelos for their comments.

\section{Appendix A: Proof of proposition 1}

The proof is similar to that of Proposition 2 of Bodie and Samuelson (1989). Consider first the no-uncertainty case. Denote $L_{I}(x, B)$ the leisure that satisfies the first-order condition with respect to $L_{i}$ given $x$ and $B$. Let $C_{I}(x, B)$ denote the consumption that satisfies the firstorder condition with respect to $C_{i}$ given $x$ and $B$. Denote $x(B)$ the optimal $x$ given $B$. In the log-utility case, we get:

$$
\begin{aligned}
& L_{i}(x, B)=\frac{L_{0}+\frac{G}{B+w}\left(B+w-C_{0}+W_{0}\left(1+x z_{i}+(1-x) r\right)\right)}{G+1} . \\
& C_{i}(x, B)=W_{0}\left(1+x z_{i}+(1-x) r\right)+(w+B)\left(1-L_{i}(B)\right) .
\end{aligned}
$$




$$
x(B)=\frac{\left(p_{1} z_{1}+p_{2} z_{2}-r\right)}{W_{0}\left(r-z_{1}\right)\left(z-r_{2}\right)}\left((B+w)\left(1-L_{0}\right)-C_{0}+W_{0}(1+r)\right)
$$

Let

$$
V(x(B), b)=p_{1}\left(z_{1}-r\right) U_{C}\left(C_{1}(x(B), b), L_{1}(x(B), b)\right)+p_{2}\left(z_{2}-r\right) U_{C}\left(C_{2}(x(B), b), L_{2}(x(B), b)\right) .
$$

By the first-order-condition with respect to $x$, we know that $V(x(B), B)=0$.

When we introduce uncertainty in Social Security benefits, the new first-order-condition with respect to $x$ is: $E_{b}[V(x(b), b)]=0$.

We can show that $V(x(B), b)$ is concave in $b$ for the class of utility functions considered in the proposition. Using Jensen inequality, we have:

$$
E_{b}[V(x(B), b)]<V\left(x\left(E_{b}(b)\right), E_{b}(b)\right)=V(x(B), B)=0 .
$$

Since $E_{b}[V(x(b), b)]$ is decreasing in $x$, we find that $x^{*}$ satisfying $E_{b}\left[V\left(x^{*}, b\right)\right]=0$ is such that $x^{*}<x(B)$.

\section{Appendix B: Fitting the subjective distributions of future Social Security benefits to parametric distributions}

We follow closely Engelberg et al. (2009) to fit respondents' answers to a parametric distribution. We use the subjective distribution provided in the unfolding bin screen for all the respondents who answered it. We make the following assumptions depending on the respondent's answers:

1. If the respondent uses one bin only, we assume that the subjective distribution has the shape of an isosceles triangle whose support is the bin.

2. If the respondent uses two bins, we consider various cases.

i. If the two bins are adjacent and each contains 10 balls, we assume that the subjective distribution has the shape of an isosceles triangle whose support is the union of the two bins.

ii. If the two bins are adjacent but contain unequal probability mass, we assume that the subjective distribution has the shape of an isosceles triangle. The support contains the bin with the higher probability mass entirely, and part of the bin with fewer probability mass to ensure that the probability allocated by the respondent within each bin is maintained.

iii. If the two bins are not adjacent (which is the case for 8 observations), we assume that the distribution is uniformly distributed within the bins with positive probability mass.

3. If the respondent uses 3 bins or more, we assume that the subjective distribution is a generalized Beta distribution. Let $T_{0}=0, T_{1}, \ldots, T_{7}$ be the thresholds for a given respondent, and let $P_{j}=P\left(S S \leq T_{j}\right), j=0, \ldots, 6$ denote the associated elicited cumulative distribution function of future Social Security benefits. The support of the beta distribution is assumed to be from zero to $U=T_{7}+T_{1}$, i.e. the right outer 
bin is assumed to be closed rather than open-ended and of similar width as the other bins. We find the parameters $a$ and $b$ of the beta distribution $B(. ; a, b, 0, U)$ that best fit the answers of respondent i using nonlinear least squares. I.e, we solve:

$$
\min _{\mu, \sigma} \sum_{j=0}^{6}\left(P_{j}-B\left(T_{j} ; a, b, 0, U\right)\right)^{2}
$$

\section{Appendix C: Expected claiming age and distribution of claiming ages}

We investigate which features of the distribution respondents report when asked for their point estimate of the age at which they expect to start receiving Social Security benefits. We focus the analysis on respondents with a point estimate between 60 and 70, and with at most 2 modes ( $97.1 \%$ of the data). We make two assumptions for this analysis:

A1 The claiming age is a discrete random variable distributed between 60 and 70 .

A2 If respondents report the average, it is provided in terms of age in years (e.g., if the average of the distribution is 65.6, the respondent would report 65).

If a respondent allocates zero probability mass to the extreme bins (which are open-ended), we can compute exactly the mean, median and mode provided that A1 and A2 hold. For respondents who allocate a positive probability to the extreme bins, we can evaluate bounds for the mean, median or mode. For example, we compute a lower (upper) bound for the mean assuming that all the probability mass allocated to the interval " 61 or less" is allocated to age 60 (61) and that all the probability mass allocated to the interval "68 or more" is allocated to age 68 (70). In some cases where the respondent allocated a small probability to the extreme bins, the upper and lower bounds for the mean are equal due to the rounding assumption posited in A2. Similarly, if a respondent allocates, for example, a $60 \%$ chance that the claiming age is " 61 or less," then the median and the mode can be 60 or 61 . Overall, for $81 \%$ of the observations, we can compute the exact mode(s), median and mean. For the remaining $19 \%$, we have a bound on at least one of these features of the distribution.

\section{References}

Bernheim, D.; Levin, L. Social Security and Personal Saving: An Analysis of Expectations. American Economic Review; Papers and Proceedings of the Hundred and First Annual Meeting of the American Economic Association; 1989. p. 97-102.

Bodie Z, Samuelson W. Labor Supply Flexibility and Portfolio Choice. NBER Working Paper No 3043. 1989

Bodie Z, Merton R, Samuelson W. Labor Supply Flexibility and Portfolio Choice in a Life-Cycle Model. Journal of Economic Dynamics and Control. 1992; 16(3-4):427-449.

Bottazzi R, Jappelli T, Padula M. The Portfolio Effect of Pension Reforms: Evidence from Italy. Journal of Pension Economics and Finance. forthcoming.

Bottazzi R, Jappelli T, Padula M. Retirement expectations, pension reforms, and their impact on private wealth accumulation. Journal of Public Economics. 2006; 90:2187-2212.

Campbell J. Household Finance. The Journal of Finance. 2006; 64:1553, 1604.

Delavande A, Rohwedder S. Eliciting Subjective Expectations in Internet Surveys. Public Opinion Quarterly. 2008; 72:866-891. [PubMed: 20862271]

Dominitz J, Manski C. Measuring Pension-Benefit Expectations Probabilistically. Labour. 2006; 20:201-236.

Dominitz J, Manski C. Using Expectations Data to Study Subjective Income Expectations. Journal of the American Statistical Association. 1997; 92:855-867. 
Engelberg J, Manski C, Williams J. Comparing the Point Predictions and Subjective Probability Distributions of Professional Forecasters. Journal of Business and Economic Statistics. 2009; 165:146-158.

Gollier, C. What Does Theory Have to Say About Household Portfolios?. In: Guiso, G.; Haliassos, M.; Jappelli, T., editors. Household Portfolios. MIT Press; 2002. p. 27-54.

Guiso L, Jappelli T, Padula M. Pension Risk, Retirement Saving and Insurance. CSEF Working Paper No 223. 2009

Gustman, AL.; Steinmeier, TL. What People Don't Know About Their Pensions and Social Security: An Analysis Using Linked Data From the Health and Retirement Study. In: Gale, WG.; Shoven, JB.; Warshawsky, MJ., editors. Public Policies and Private Pensions. Washington, D.C.: Brookings Institution; 2004.

Lusardi A, Mitchell O. Financial Literacy and Retirement Preparedness. Evidence and Implications for Financial Education Programs. Business Economics. 2007:35-44.

Merton, RC. Continuous-Time Finance. Blackwell Publishers; Cambridge, MA: 1990.

U.S. Social Security Administration. Annual Statistical Supplement. 2009. www.socialsecurity.gov/ policy/docs/statcomps/supplement/2009/ 


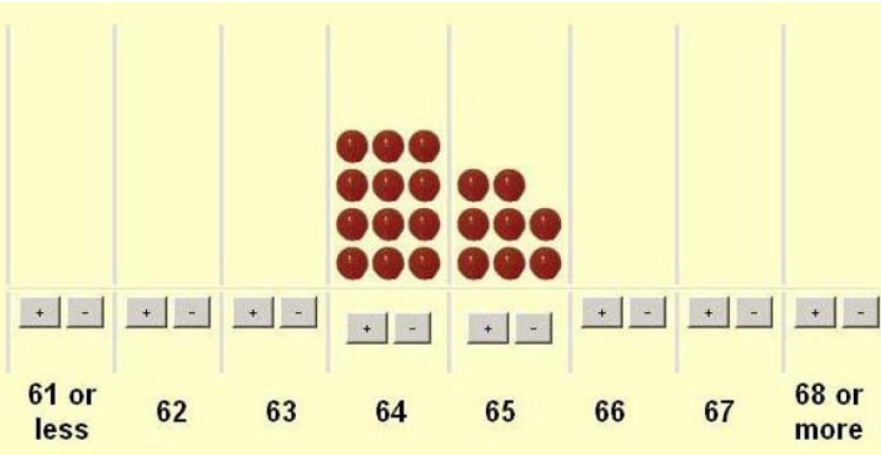

In this example, there are no balls in the ranges below 64 or above 66 , so for this person it is certain that benefits will not be collected before turning age 64 and after turning age 66 . 12 out of 20 balls are in the bin 64 meaning that the chance that benefits are collected on or after the 64th and before the 65th birthday is 12 out of 20 (60 percent). There is a smaller chance, 8 out of 20 ( 40 percent), that benefits are collected at age 65 . Of course this is just an example to illustrate; the chances you have in mind may be completely different. Now it's your turn! Choose next to start allocating balls.

<<Back Next>>

Figure 1. Introductory example to visual format about future Social Security claiming age 


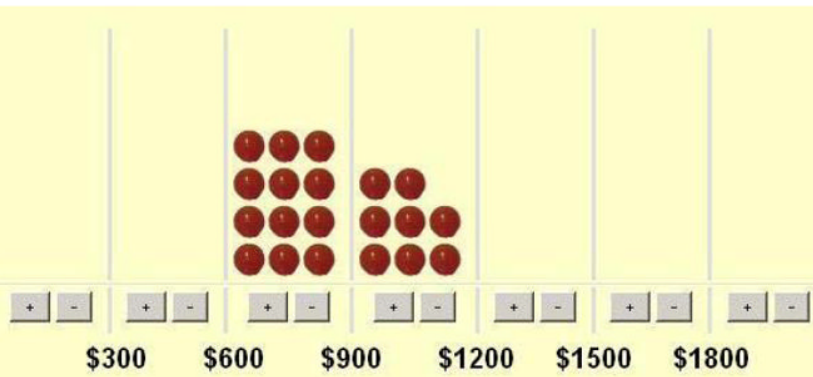

In this example, there are no balls in the ranges below $\$ 600$ or above $\$ 1200$, so it is certain that benefits will not be lower than $\$ 600$ or higher than $\$ 1200.12$ out of 20 balls are in the bin $\$ 600$ - $\$ 900$ meaning that the chance that benefits are between $\$ 600$ and $\$ 900$ is 12 out of 20 ( 60 percent). There is a smaller chance, 8 out of 20 ( 40 percent), that benefits are between $\$ 900$ and $\$ 1200$. Of course this is just an example to illustrate; the chances you have in mind may be completely different. Now it's your turn! Choose next to start allocating balls.

$<<$ Back Next $>>$

Figure 2. Introductory example to visual format about future Social Security benefits 
Table 1

Descriptive statistics

\begin{tabular}{|c|c|c|c|c|}
\hline & Mean & $25^{\text {th }}$ perc. & Median & $7^{\text {th }}$ perc. \\
\hline Age & 55.95 & 54 & 56 & 59 \\
\hline Female & 0.62 & 0 & 1 & 1 \\
\hline Married & 0.78 & 1 & 1 & 1 \\
\hline Years of education & 14.43 & 12 & 14 & 16 \\
\hline Fraction of wealth held in stocks & 0.14 & 0 & 0.03 & 0.22 \\
\hline Distance to expected claiming age & 9.55 & 5 & 9 & 12 \\
\hline Currently working for pay & 0.84 & 1 & 1 & 1 \\
\hline Number of years worked & 29.32 & 22 & 31 & 38 \\
\hline Has an employer pension plan & 0.49 . & 0 & 0 & 1 \\
\hline Measure of risk aversion (from 1 to 4,4 being most risk averse) & 3.31 & 3 & 4 & 4 \\
\hline \multicolumn{5}{|l|}{ Social Security Expectations } \\
\hline Chance of receiving Social Security in the future & 78.68 & 62 & 90 & 100 \\
\hline Expected claiming age & 64.82 & 62 & 65 & 66 \\
\hline Standard deviation of distribution of claiming ages & 0.74 & 0.11 & 0.67 & 1.20 \\
\hline \multicolumn{5}{|l|}{ Expectations conditional on expected claiming age } \\
\hline Reported expected Social Security benefit conditional on eligibility & 1145.56 & 750 & 1000 & 1500 \\
\hline Mean of fitted Social Security benefit distribution conditional on eligibility & 1140.49 & 716.91 & 1011.05 & 1140.47 \\
\hline Standard deviation of fitted Social Security benefit distribution conditional on eligibility & 100.42 & 34.70 & 49.47 & 118.14 \\
\hline Standard deviation of fitted Social Security benefit distribution unconditional on eligibility & 79.63 & 29.09 & 42.79 & 89.95 \\
\hline \multicolumn{5}{|l|}{ Expectations unconditional on expected claiming age } \\
\hline Expected Social Security benefit conditional on eligibility & 1164.25 & 750 & 1100 & 1500 \\
\hline Mean of fitted Social Security benefit distribution conditional on eligibility & 1081.17 & 682.15 & 1002.50 & 1400.00 \\
\hline Standard deviation of fitted Social Security benefit distribution conditional on eligibility & 108.72 & 47.06 & 79.61 & 134.68 \\
\hline Standard deviation of fitted Social Security benefit distribution unconditional on eligibility & 91.65 & 36.74 & 65.93 & 111.74 \\
\hline \multicolumn{5}{|l|}{ Other subjective expectations } \\
\hline Chance of losing job during next year & 13.85 & 0 & 5 & 20 \\
\hline Chance of change in Social Security in the next 10 years & 63.68 & 50 & 60 & 90 \\
\hline Chance that health will be the same as now as in 4 years & 73.09 & 60 & 80 & 90 \\
\hline Chance of a recession in the next 10 years & 44.40 & 20 & 50 & 60 \\
\hline Chance that shares rise faster than cost of living in next 10 years & 46.96 & 25 & 50 & 70 \\
\hline Chance that shares rise more than $8 \%$ per year in next 10 years & 41.88 & 20 & 45 & 55 \\
\hline Chance to survive until age 75 divided by life table probability & 0.94 & 0.72 & 1.02 & 1.17 \\
\hline
\end{tabular}

The number of observations varies across variables ranging between 313 and 1,479. We present the statistics for each variable over the sample for which it is available combined with any other sample restrictions applicable to the subsequent analyses where this variable appears. For example, for Social Security benefit expectations conditional on claiming age the number of observations is $N=316$; for the chance of receiving Social Security in the future the number of observations is $\mathrm{N}=1,479$. 
Table 2

Best Linear Predictors under Square Loss of Social Security Expectations

\begin{tabular}{|c|c|c|c|c|}
\hline & \multirow[t]{2}{*}{$\begin{array}{l}\text { Chance of receiving } \\
\mathrm{SS} \text { in the future }\end{array}$} & \multirow{2}{*}{$\begin{array}{l}\text { Mean of fitted SS benefit } \\
\text { distribution conditional } \\
\text { on eligibility }\end{array}$} & \multicolumn{2}{|c|}{$\begin{array}{c}\text { Standard deviation of fitted SS benefit distribution } \\
\text { conditional on eligibility }\end{array}$} \\
\hline & & & Unconditional on ECA & Conditional on ECA \\
\hline Female & $-0.231[1.538]$ & $-342.078^{* * *}[41.955]$ & $-41.029^{* * * *}[9.893]$ & $-37.457^{* *}[14.604]$ \\
\hline Married & $0.366[1.791]$ & $-79.500[51.007]$ & $11.225[12.273]$ & $-38.608^{* *}[17.752]$ \\
\hline Less than 50 years old & -- & -- & -- & -- \\
\hline 50 to 54 & $9.366^{* *}[2.903]$ & $12.613[72.576]$ & $10.053[16.130]$ & $-28.693[28.201]$ \\
\hline 55 to 59 & $15.930^{* * *}[2.800]$ & $-22.503[71.748]$ & $14.357[19.833]$ & $-5.042[32.468]$ \\
\hline $60+$ & $14.906^{* * * *}[3.267]$ & $-9.532[86.798]$ & $22.759[24.544]$ & $-16.668[39.589]$ \\
\hline High-school or less & -- & -- & -- & -- \\
\hline Some college & $-2.668[1.898]$ & $21.153[51.286]$ & 2.903 [11.917] & $8.573[18.062]$ \\
\hline College and more & $-0.854[1.875]$ & $193.523^{* * *}[50.638]$ & $2.039[12.292]$ & $27.993[17.259]$ \\
\hline Above median wealth & $-0.299[1.545]$ & 53.164 [41.917] & $15.407[10.042]$ & $14.965[14.312]$ \\
\hline Working for pay & $7.726^{* *}[2.595]$ & $118.110^{*}[70.334]$ & $-25.535[16.388]$ & $4.559[26.053]$ \\
\hline Number of years worked & $0.295^{* * *}[0.078]$ & $6.059^{* *}[2.193]$ & $-0.042[0.552]$ & $-0.255[0.766]$ \\
\hline $\begin{array}{l}\text { Self-rated health excellent/ } \\
\text { very good }\end{array}$ & -- & -- & -- & -- \\
\hline Good & $-3.472^{* *}[1.718]$ & $44.054[46.399]$ & $-6.778[10.366]$ & $-12.709[17.566]$ \\
\hline Poor/fair & $0.037[2.660]$ & $-42.471[73.886]$ & $-24.223[17.787]$ & $1.445[25.529]$ \\
\hline $\begin{array}{l}\text { Chance that in } 4 \text { years health } \\
\text { same as now }\end{array}$ & $0.018[0.018]$ & $0.549[0.496]$ & $-0.399[0.319]$ & $-0.337[0.458]$ \\
\hline $\begin{array}{l}\text { Chance of losing job during } \\
\text { next year }\end{array}$ & $0.012[0.041]$ & $-0.081[1.125]$ & $-0.046[0.269]$ & $0.647^{*}[0.385]$ \\
\hline $\begin{array}{l}\text { Chance of a recession in the } \\
\text { next } 10 \text { years }\end{array}$ & $-0.066^{* *}[0.027]$ & $-0.640[0.764]$ & $-0.141[0.179]$ & $-0.101[0.270]$ \\
\hline $\begin{array}{l}\text { Chance of SS reform in next } \\
10 \text { years }\end{array}$ & $-0.051^{* * *}[0.026]$ & $-1.756^{* *}[0.746]$ & $0.169[0.173]$ & $0.065[0.270]$ \\
\hline $\begin{array}{l}\text { Distance from ECA: less than } \\
5 \text { years }\end{array}$ & & & -- & -- \\
\hline 6 to 10 years & & & $27.900^{* *}[13.468]$ & $21.716[20.783]$ \\
\hline More than 10 years & & & $57.170^{* *}[18.415]$ & $64.514^{* *}[26.536]$ \\
\hline $\begin{array}{l}\text { Standard deviation for } \\
\text { claiming age }\end{array}$ & & & $70.340^{* *}[21.720]$ & \\
\hline $\begin{array}{l}\text { Standard deviation for } \\
\text { claiming age missing }\end{array}$ & & & $67.405^{* * * *}[18.710]$ & \\
\hline $\begin{array}{l}\text { Elicitation format: } \\
\text { conditional on a claiming age }\end{array}$ & & $64.263[41.279]$ & & \\
\hline Constant & $60.164^{* * * *}[5.167]$ & $1121.982^{* * *}[141.025]$ & $61.482[46.091]$ & $139.225^{* *}[65.838]$ \\
\hline $\mathrm{N}$ & 1477 & 742 & 428 & 314 \\
\hline
\end{tabular}

Robust standard errors in brackets. Regressions include indicators for missing variables.

significant at $10 \%$; 
*** ${ }^{*}$ ignificant at $5 \%$;

**** significant at $1 \%$.

ECA $=$ expected claiming age SS = Social Security . 
Table 3

Best Linear Predictors under Square Loss of the Fraction of Wealth held in Stocks

\begin{tabular}{|c|c|c|c|}
\hline & & $\begin{array}{l}\text { Unconditional on expected } \\
\text { claiming age }\end{array}$ & $\begin{array}{l}\text { Conditional on expected } \\
\text { claiming age }\end{array}$ \\
\hline \multicolumn{2}{|c|}{ Standard deviation of the distribution of Social Security benefits (in $\$ 1,000$ ) } & $-0.065[0.131]$ & $-0.203^{* *}[0.100]$ \\
\hline \multicolumn{2}{|c|}{ Chance that stock prices rise faster than cost of living in next 10 years } & $0.001[0.000]$ & $0.001 *[0.001]$ \\
\hline \multicolumn{2}{|c|}{ Chance that stock prices rise more than $8 \%$ per year in next 10 years } & $0.001 *[0.000]$ & $-0.001[0.001]$ \\
\hline \multicolumn{2}{|c|}{ Chance of a recession in the next 10 years } & $-0.000[0.000]$ & $-0.002^{* * *}[0.000]$ \\
\hline \multicolumn{4}{|c|}{ Other wealth ${ }^{a}(\mathrm{OW})$ and Social Security wealth (SSW) } \\
\hline & High OW, high SSW & -- & -- \\
\hline & Low OW, low SSW & $-0.134^{* * *}[0.030]$ & $-0.099^{* *}[0.035]$ \\
\hline & Low OW, high SSW & $-0.135^{* * *}[0.032]$ & $-0.098^{* *}[0.041]$ \\
\hline & High OW, low SSW & $-0.021[0.034]$ & $-0.083^{* *}[0.041]$ \\
\hline \multicolumn{2}{|l|}{ Female } & $0.005[0.020]$ & $0.024[0.025]$ \\
\hline \multicolumn{2}{|l|}{ Married } & $0.052^{* *}[0.022]$ & $0.004[0.030]$ \\
\hline \multirow[t]{4}{*}{ Age } & Less than 50 years old & -- & -- \\
\hline & 50 to 54 & $0.085^{* *}[0.031]$ & $0.053[0.038]$ \\
\hline & 55 to 59 & $0.046[0.029]$ & $0.091^{* *}[0.037]$ \\
\hline & $60+$ & $0.088^{* *}[0.034]$ & $0.113^{* *}[0.045]$ \\
\hline \multicolumn{2}{|c|}{ Chance to survive until age 75 divided by life table probability } & $0.004[0.029]$ & $0.036[0.029]$ \\
\hline \multirow[t]{3}{*}{ Education } & High-school or less & -- & -- \\
\hline & Some college & $-0.015[0.023]$ & $-0.025[0.025]$ \\
\hline & College and more & $0.061^{* *}[0.028]$ & $0.090^{* *}[0.030]$ \\
\hline \multirow[t]{4}{*}{ Risk aversion } & Lowest & -- & -- \\
\hline & Next to lowest & $-0.045[0.037]$ & $-0.083^{*}[0.046]$ \\
\hline & Next to highest & $-0.038[0.038]$ & $-0.037[0.047]$ \\
\hline & Highest & $-0.020[0.032]$ & $-0.026[0.040]$ \\
\hline \multicolumn{2}{|c|}{ Has employer pension plan } & $-0.026[0.020]$ & $-0.004[0.024]$ \\
\hline \multicolumn{2}{|l|}{ Constant } & $0.093[0.071]$ & $0.153^{*}[0.084]$ \\
\hline \multicolumn{2}{|l|}{$\mathrm{N}$} & 425 & 314 \\
\hline
\end{tabular}

${ }^{a}$ Other wealth is the same as total bequeathable wealth which we defined as the sum of housing, other real estate, transportation, IRAs, stocks and stock mutual funds, checking and savings, CDs, bonds, and other assets, minus all debt (mortgages, home equity loans and any other debt).

Robust standard errors in brackets.

significant at $10 \%$;

*** significant at $5 \%$;

**** significant at $1 \%$.

Regressions include indicators for missing variables. 